\title{
Best Practices: Caregiver Training Resources Derived from Remote Behavioral Service Delivery within the Foster Care System
}

\author{
Emma K. King ${ }^{1}$, Angelyn R. Harrell ${ }^{2}$, \\ and Sarah M. Richling ${ }^{1}$ \\ ${ }^{1}$ Auburn University \\ ${ }^{2}$ Alabama Psychiatric Medication Review Team
}

\begin{abstract}
Author Note
Correspondence should be addressed to the third author at Department of Psychological Sciences, 226 Thach Hall, Auburn University, AL 36849-5214 (email: smr0043@auburn.edu).
\end{abstract}




\begin{abstract}
In the face of COVID-19 and necessary shifts in service delivery for behavior analysts, caregiver involvement in behavioral interventions will likely increase. Resources caregivers can consume and implement independently are critical in helping caregivers manage behavior in their homes. This paper includes antecedent and consequent behavior management strategies which correspond with provided written instructions and video tutorials designed for caregivers. The materials presented within this paper were originally produced and found effective in aiding caregivers managing behavior in the home within the Alabama foster care system. Although individuals within this system are at a higher risk of abuse and neglect and may engage in higher levels of aberrant behavior, we are distributing this document in hopes it will help behavior analysts working across a variety of populations as they navigate changes in service delivery and adopt resources for continued care and caregiver training.

Keywords: caregiver training, foster care, behavioral interventions, resources for caregivers, COVID-19
\end{abstract}




\section{Best Practices: Caregiver Training Resources Derived from Remote Behavioral Service Delivery within the Foster Care System}

\section{Editor's Note}

This manuscript is being published on a highly expedited basis, as part of a series of emergency publications designed to help practitioners of applied behavior analysis take immediate action to adjust to and mitigate the COVID-19 crisis. This article was submitted on 4/2/20 and received final acceptance on 04/17/20. The journal would like to especially thank Dr. Matthew Brodhead for his expeditious review of the manuscript. It is important to note that general tips for behavior management and parent training are in no way a substitute for functionbased assessment and treatment by a behavior analyst. Nevertheless, we believe the tools contained in this article will be useful to the families we serve, especially in this moment of increased parental demands and stress. The views and strategies suggested by the articles in this series do not represent the positions of the Association for Behavior Analysis, International or Springer Nature.

\section{Introduction}

Professionals in the field of behavior analysis have long suggested family and caregiver involvement is an important component of effective intervention. Professionals recommend practitioners give caregivers of clients diagnosed with Autism Spectrum Disorder (ASD) ample information and education to support their participation in their child's services (Educating Children with Autism, 2001). While these professionals do not suggest caregivers be the sole intervention agents for their children, the current world-wide pandemic, the COVID-19 virus, has severely limited families’ access to in-person services. 
As governments and health organizations mandate social distancing to prevent virus spread, children are spending an increased number of hours at home, with only caregivers and family members to modify their maladaptive behavior or teach new skills. Behavior analytic service modalities must change. There are several evidence-based behavioral procedures which may be helpful for caregivers to receive exposure to as soon as possible. These strategies may aid caregivers as they learn to manage households during the current pandemic, especially those with children who may be facing changes in behavioral services.

Additionally, measures to ensure social distancing, such as working from home and school closures, are putting strains on children and the agencies whose function is to protect them. With families experiencing greater life and economic stressors and children spending significantly more time at home, children are at a greater risk for abuse and neglect (Duggan et al., 2004; Slack et al., 2004). The same measures also distance at-risk children from common reporters of maltreatment (e.g., school personnel) resulting in fewer reports to child protective services during this time. Meanwhile, multiple states across the United States are reporting stress on child protective services and the foster care system in the wake of this virus, the very systems meant to protect children from abuse and neglect (Rae, 2020; Knowles, 2020; Brindley, 2020). Current and potential foster caregivers are unable to attend in-person training, while foster children may experience additional trauma due to frequent placement disruptions or inability to communicate with biological family or friends (Fecteau, 2020).

Practitioners from the Alabama Psychiatric Medication Review Team (APMRT), a collaboration project between Auburn University and the Alabama Department of Human Resources, work with children in foster care and children at risk of being removed from their home. The primary function of APMRT is to provide behavioral interventions for challenging 
behavior and reduce the use of unnecessary psychotropic medication with foster youth. Members of APMRT wrote this literature review to inform the intervention recommendations given to foster caregivers and biological caregivers receiving behavioral services and to provide remote information to caregivers still on the waitlist for in-person services. In the wake of COVID-19, most of these services are temporarily suspended. Therefore, the purpose of the current paper is to disseminate this list of evidence-supported practices, a corresponding written guide on intervention recommendations, and instructional videos describing the interventions (see appendix) as a resource for caregivers, social workers, or behavior analysts as they transition to remote, at-home service delivery.

\section{Using and Interpreting Materials}

The written intervention guide and instructional video tutorials can be helpful tools during the COVID-19 pandemic because they were adapted specifically for remote caregiver training. Authors derived all strategies from published, behavior analytic research, organized them into four categories (see list below), and present them in easily-consumable, second-person language. Each category of strategies is linked to a corresponding, free-access online video tutorial which provides further explanation and practical examples of each strategy. In addition, each video tutorial includes a comprehension quiz, such that practitioners can assess caregivers’ understanding of the material. Authors provide separate sections of the written guide here (see appendix for entire written guide in printable format), with additional information practitioners can utilize in supporting these recommendations while training caregivers or informing other stakeholders. 


\section{Strategies to Build a Positive Environment in Your Home}

These will help encourage those good behaviors they are doing and can make your home a more positive environment!

1.

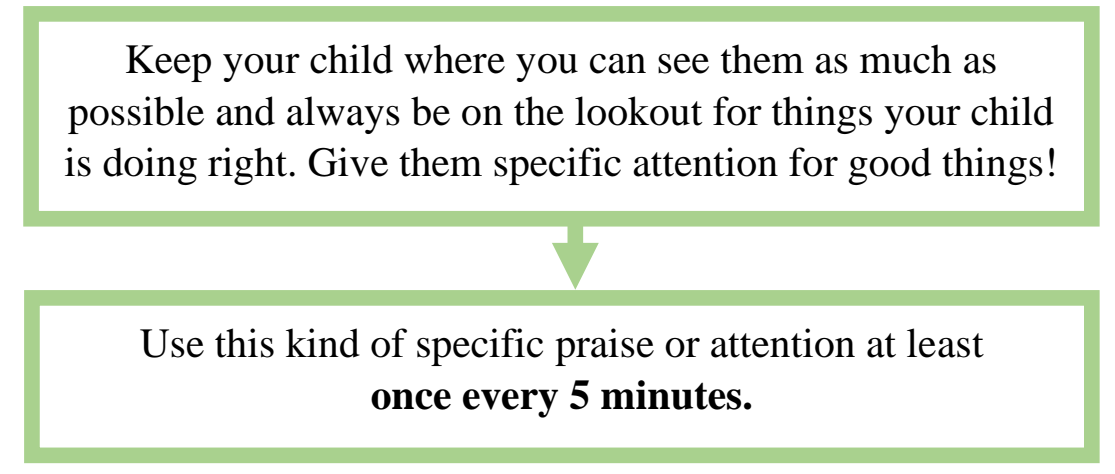

Example: "Hey, Jimmy! That's a cool block tower, thanks for playing quietly!”

Example: "Do you want to color with markers or crayons today?”

3.

2. Provide choices whenever possible.

2.

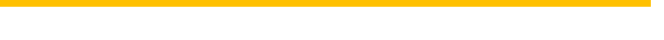

wio
Example: "First we are going to clean up, then we can go play outside."

\section{Strategies for responding to your child's requests}

These will teach and encourage always asking appropriately, and how to handle being told no. Modify however your child communicates!

When your child asks for something nicely, compliment their nice asking!

-If you can, give them what they asked for

-If you can't give them what they asked for, offer a choice of something else OR use a first $\rightarrow$ then statement to let them know when they can have it.

When your child asks for something the wrong way (by yelling, whining, or taking something from someone), don't give them what they asked for.

-Wait until they are quiet and listening to you, then remind them how to ask nicely for something they can have
Example: “Thanks for asking so nicely! We aren't having popsicles today though; you can have fruit snacks or a cookie."

OR

"Thanks for asking kindly, first we have to finish all our chores, then we can have a Popsicle.”

Example: “Jimmy, you can say 'May I have fruit snacks or a cookie, please?'” 
- Supporting statements for "Strategies to build a positive environment in your home" and “Strategies for responding to your child's requests” include:

o Giving regular, positive attention can increase compliance with directives (Speights Roberts et al., 2008)

o Giving choices about non-essential components of a task or letting the child choose the order of tasks to complete can reduce problem behavior (Cole and Levinson, 2002; Kern et al., 2001)

o Using first-then statements and providing contingent access to preferred items and activities can increase compliance and routine-following (Mace et al., 2013; Homme et al., 1963; Lalli et al., 1995)

o Providing alternative preferred tasks when a child's request is unavailable can decrease problem behavior (Mace et al., 2013) 


\section{How to Give Instructions - Short, Do, and Follow Through}

When giving your child an instruction:

- Start by giving your child some positive attention or getting them to look at you; you can get on your child's level, touch their shoulder, and tell them what they're doing well at that moment. You may need to block them from playing with toys or watching the TV.

- Use short instructions

- Only give one instruction at a time

- Tell your child what to do instead of saying "Stop that" or "Don't do that" (this will help teach your child the right thing to do next time)

- Follow through on your instruction remembering to praise!

Tip: Use the phrase "Short, Do, and Follow Through" to help you remember.

When possible, use choices in your instructions.

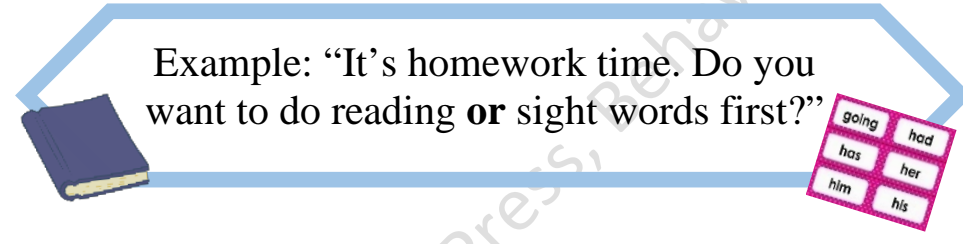

You can also use first $\rightarrow$ then statements when giving your child something to do.

Example: "First take out the trash, then you can watch TV."

\section{A good instruction:}

You want Jimmy to stop playing. "Jimmy, put your toys in the box.”
How to follow through: Three-Step Prompting

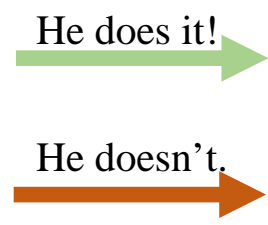

Great job, Jimmy!

Say, "like this" and show him how using one or two toys.
If he still doesn't do what you showed him, take Jimmy's hand in yours and do it with him. 
- Supporting statements for "How to give instructions - Short, Do, Follow through" include:

o Delivering the direction less than $5 \mathrm{ft}$ away from the child, requesting eye contact from the child prior to instruction delivery, using directive statements instead of questions, using descriptive wording to give the instruction, and allowing $5 \mathrm{~s}$ for the child to respond increases compliance (Speights Roberts et al., 2008;

Stephenson and Hanley, 2010)

o Using choices and contingent access to preferred items and activities can increase compliance (Cole and Levinson, 2002; Homme et al., 1963)

o Following through using three-step prompting increases compliance and reduces the need for more prompting in the future (Stephenson and Hanley, 2010; Tarbox et al., 2007)

o Praise contingent on following directions can increase compliance (Speights Roberts et al. (2008) 


\section{How to Handle Junky Behavior - Pivot and Praise}

Follow these steps when your child is doing something annoying or disrespectful, but not dangerous. For example, you can use these steps for things like whining, rolling their eyes at you, making bodily-function noises, or teasing a sibling.

1. Don't comment on the annoying behaviors

2. If there's another person in the room doing the right thing, compliment them.

\section{"Sally, great job using a polite voice at the dinner table."}

3. If the original child stops doing the annoying thing, notice and compliment them immediately for doing the right thing!

\section{“Jimmy, I really like how nice and polite you’re being.”}

If there isn't another person in the room, only do steps 1 and 3. Just wait it out and give your child specific attention for the right behavior as soon as they stop the annoying behavior.

- Supporting statement for "How to handle junky behavior - pivot and praise:”

o Withholding attention for undesired, non-dangerous behavior and saving attention for the child's appropriate behavior or another child’s appropriate behavior can decrease undesired behavior (Hester et al., 2009; Hall et al., 1971) 


\section{How to Handle Major Problem Behaviors}

Follow these steps when your child is doing something harmful or dangerous, like being aggressive, throwing a tantrum, damaging things in the house, or hitting themselves.

1. Stay calm - minimize comments on the behavior, keep your tone of voice down, minimize any damage by taking away items they may be hitting others or themselves with and standing between them and another child they could hurt.

2. Stand your ground - keep your child from getting what they want, don't give them what they're asking for while they're hitting, throwing tantrums, etc.

3. If you were giving them an instruction before they started having major problem behavior...

Follow through by guiding them through the task

If they were trying to get something they wanted before they started having major problem behavior...

Wait for them to be calm, compliment/give attention for being calm, and remind them to ask the right way for what they want (if they can have it now) or tell them when they can have it later or what they can have instead.

“Jimmy, I really like your inside voice. You can ask, 'Can I have a popsicle, please?’”
"Jimmy, thank you for sitting quietly. You can have fruit snacks today.”

- Supporting statements for "How to handle major problem behavior” include:

o Using extinction (withholding preferred items, activities, and extra attention) paired with prompting the child to appropriately communicate their wants can decrease problem behavior in the future (Shukla and Albin, 1996)

o Keeping demands in place and following through can reduce escape-maintained behavior in the future (Tarbox et al., 2007) 
Authors present all the above sections in complete documents in the appendix. For practitioner who decide to limit the number of strategies they provide to caregivers, see below for strategies categorized by three problem behavior functions.

- Attention-maintained behavior

o Strategy number one from "strategies to build a positive environment in your home”

o "How to give instructions - Short, Do, Follow through"

o "How to handle junky behavior - pivot and praise"

- Tangible-maintained behavior

o Strategy number three from "strategies to build a positive environment in your home”

o "Strategies for responding to your child's request"

o "How to give instructions - Short, Do, Follow through"

o "How to handle major problem behavior"

- Escape-maintained behavior

o Strategy two from "strategies to build a positive environment in your home"

o "How to give instructions - Short, Do, Follow through"

o "How to handle major problem behavior"

To aid in caregiver training using the materials provided within this manuscript, authors suggest practitioners follow or modify one of the flow charts presented here: 


\section{Figure 1}

Modified behavioral skills training (BST) using all materials

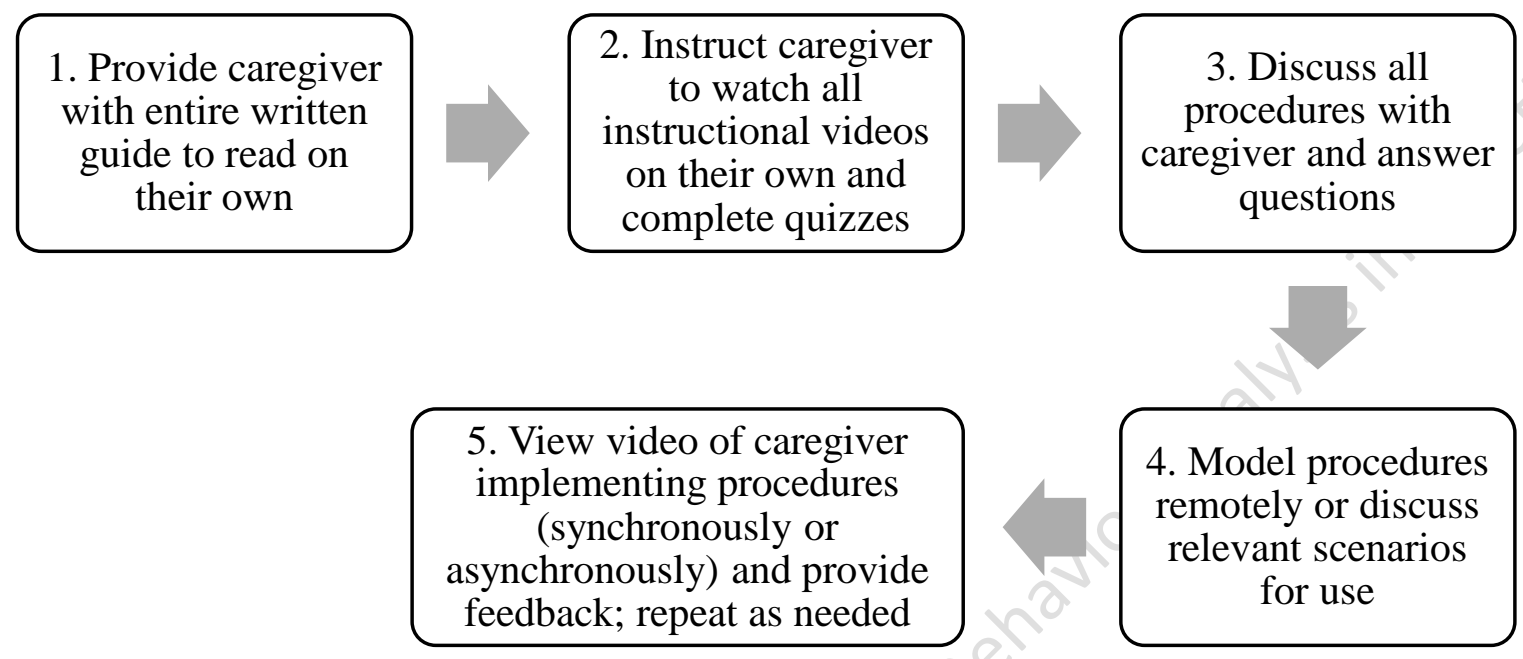

Note: Caregiver completes instruction phase independently, for all strategies. Practitioner involvement begins at step 3, where supporting statements may be useful. 


\section{Figure 2}

Remote BST using all materials

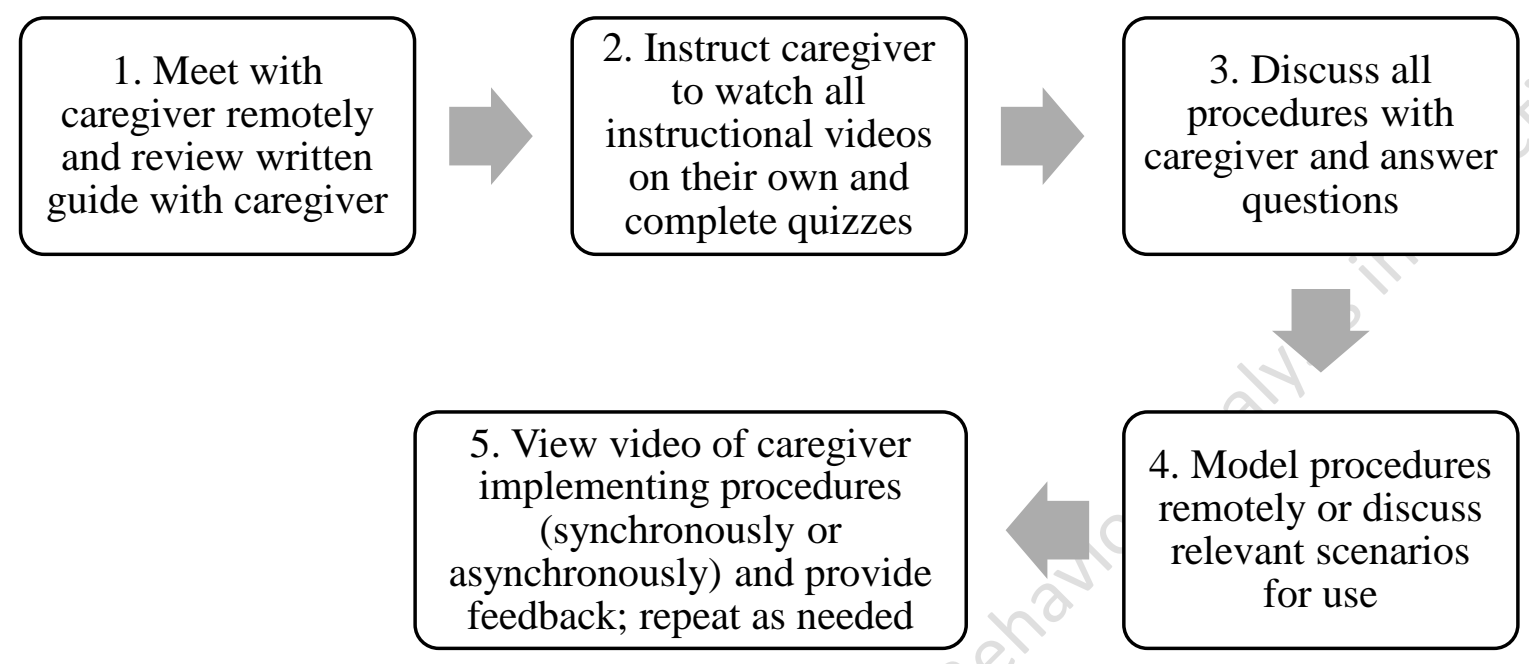

Note: Practitioner involvement begins at step 1, where supporting statements may be useful. This training procedure includes a more resource-intensive instruction phase than Figure 1. 


\section{Figure 3}

Single-strategy BST

1. Provide caregiver with a single setion of the guide to read on their own

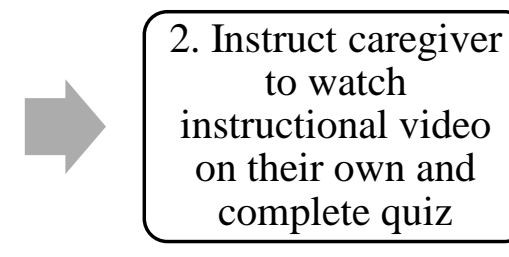

5. View video of caregiver implementing procedures (synchronously or asynchronously) and provide feedback; repeat as needed
3. Discuss procedures with caregiver and answer questions

4. Model procedures remotely or discuss relevant scenarios for use

Note: Caregiver completes instruction phase independently, for one section of strategies.

Practitioner involvement begins at step 3, where supporting statements may be useful. This training procedure can be repeated for all relevant sections of the guide.

\section{Concluding Remarks}

These strategies, and training caregivers using BST, has proved useful for APMRT clinicians working with children of multiple ages and with different diagnoses inside foster and biological homes. These strategies and training procedures can readily be extended to other settings and contexts that behavior analysts are currently adapting to during this pandemic. APMRT clinicians often modify or add to the procedures in the appendix, as needed, to meet individual needs of the client and their household. While the existing research and APMRT's effective generalization of these procedures to a novel population suggest these procedures may be likely to work for most clients and families, authors created the attached written guide and 
corresponding videos to serve as the instruction portion of behavioral skills training, not for use as the sole intervention prescribed by behavior analysts.

The written guide includes brief recommendations in second-person language so professionals in the field may be able to distribute the document for caregivers to consume on their own. The online instructional videos provide further details and describe the written guide with some example scenarios. However, behavior analysts using these materials should ensure caregivers understand and can implement the enclosed procedures without causing harm to themselves or their children. Authors encourage caregivers who access these materials on their own to seek support from behavior analytic professionals should they have any questions or concerns.

With the increase in the number of hours children are spending at home and the decreased availability of in-person services due to the COVID-19 virus, caregivers are becoming more responsible for managing behavior and teaching new skills in the home. Resources caregivers can access and consume independently are essential in continuing to provide behavior analytic services. It is the authors' hope that this review, and the tutorial materials contained within, may be helpful in aiding both caregivers and practitioners in this transition to at-home intervention. 


\section{References}

Brindley, E. (2020, March 29). Vulnerable children at greater risk of abuse, neglect as coronavirus isolates families. Retrieved from https://www.courant.com/coronavirus/hcnews-coronavirus-child-abuse-neglect-20200329-p2k3to6ukrbltm2n2va3ndbbimstory.html

Cole, C. L., \& Levinson, T. R. (2002). Effects of within-activity choices on the challenging behavior of children with severe developmental disabilities. Journal of Positive Behavior Interventions, 4, 29-37, 52. https://doi.org/10.1177/109830070200400106.

Duggan, A., Fuddy, L., Burrell, L., Higman, S. M., McFarlane, E., Windham, A., \& Sia, C. (2004). Randomized trial of a statewide home visiting program to prevent child abuse: Impact in reducing parental risk factors. Child abuse \& neglect, 28(6), 623-643. https://doi.org/10.1016/j.chiabu.2003.08.007.

Fecteau, O. (2020, March 19). Foster care children at risk during COVID-19 pandemic. News 5 Cleveland. https://www.news5cleveland.com/news/coronavirus/foster-care-children-atrisk-during-covid-19-pandemic

Hall, R. V., Fox, R., Willard, D., Goldsmith, L., Emerson, M., Owen, M., ... Porcia, E. (1971). The Teacher as Observer and Experimenter in the Modification of Disputing and TalkingOut Behaviors1. Journal of Applied Behavior Analysis, 4(2), 141-149. https://doi.org/10.1901/jaba.1971.4-141.

Hester, P. P., Hendrickson, J. M., \& Gable, R. A. (2009). Forty years later — The value of praise, ignoring, and rules for preschoolers at risk for behavior disorders. Education and Treatment of Children, 32(4), 513-535. https://doi.org/10.1353/etc.0.0067. 
Homme, L. E., Debaca, P. C., Devine, J. V., Steinhorst, R., \& Rickert, E. J. (1963). Use of the Premack principle in controlling the behavior of nursery school children. Journal of the Experimental Analysis of Behavior. https://doi.org/10.1901/jeab.1963.6-544.

Kern, L., Mantegna, M. E., Vorndran, C. M., Bailin, D., \& Hilt, A. (2001). Choice of task sequence to reduce problem behaviors. Journal of Positive Behavior Interventions, 3, 310. https://doi.org/10.1177/109830070100300102.

Knowles, H. (2020, March 26). COVID-19 pandemic creates shortage of foster parents. WWMT Newschannel 3. https://wwmt.com/news/coronavirus/covid-19-pandemic-creates-ashortage-of-foster-parents

Lalli, J. S., Casey, S., \& Kates, K. (1995). Reducing escape behavior and increasing task completion with functional communication training, extinction and response chaining. Journal of Applied Behavior Analysis, 28(3), 261-268. https://doi.org/10.1901/jaba.1995.28-261.

Mace, F. C., Pratt, J. L., Prager, K. L., \& Pritchard, D. (2011). An evaluation of three methods of saying "no” to avoid an escalating response class hierarchy. Journal of applied behavior analysis, 44(1), 83-94. https://doi.org/10.1901/jaba.2011.44-83.

National Research Council. (2001). Educating children with autism. National Academies Press.

Rae, J. (2020, March 26). Alabama foster care system feeling affects from the COVID-19 outbreak. WFSA News. https://www.wsfa.com/2020/03/26/alabama-foster-care-systemfeeling-affects-covid-outbreak/

Shukla, S., \& Albin, R. W. (1996). Effects of extinction alone and extinction plus functional communication training on covariation of problem behaviors. Journal of Applied Behavior Analysis, 29(4), 565-568. https://doi.org/10.1901/jaba.1996.29-565. 
Slack, K. S., Holl, J. L., McDaniel, M., Yoo, J., \& Bolger, K. (2004). Understanding the Risks of Child Neglect: An Exploration of Poverty and Parenting Characteristics. Child Maltreatment, 9(4), 395-408. https://doi.org/10.1177/1077559504269193.

Speights Roberts, D., Tingstrom, D. H., Olmi, D. J., \& Bellipanni, K. D. (2008). Positive Antecedent and Consequent Components in Child Compliance Training. Behavior Modification, 32(1), 21-38. https://doi:10.1177/0145445507303838.

Stephenson, K. M., \& Hanley, G. P. (2010). Preschoolers’ compliance with simple instructions: A descriptive and experimental evaluation. Journal of Applied Behavior Analysis, 43(2), 229-247. https://doi.org/10.1901/jaba.2010.43-229.

Tarbox, R. S., Wallace, M. D., Penrod, B., \& Tarbox, J. (2007). Effects of three-step prompting on compliance with caregiver requests. Journal of Applied Behavior Analysis, 40(4), 703706. https://doi.org/10.1901/jaba.2007.703-706. 


\section{Appendix}

\section{Strategies to Build a Positive Environment in Your Home}

These will help encourage those good behaviors they are doing and can make your home a more positive environment!

4.

Keep your child where you can see them as much as possible and always be on the lookout for things your child is doing right. Give them specific attention for good things!

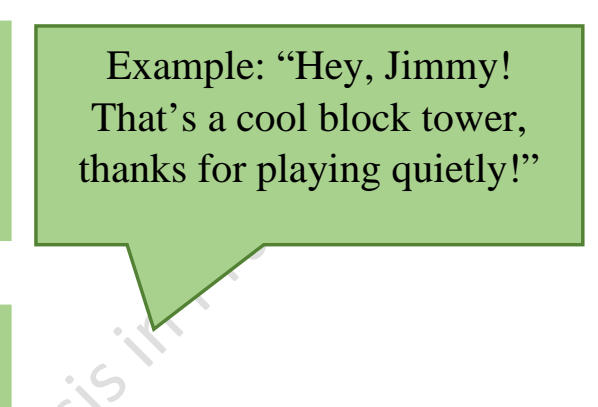

Use this kind of specific praise or attention at least once every 5 minutes.

5. $\quad$ Provide choices whenever possible.

Example: "Do you want to color with markers or crayons today?”

6.

Use First $\rightarrow$ Then statements to provide clear expectations and when giving instructions

Example: "First we are going to clean up, then we can go play outside.”

\section{Strategies for responding to your child's requests}

These will teach and encourage always asking appropriately, and how to handle being told no. Modify however your child communicates!

When your child asks for something nicely, compliment their nice asking!

-If you can, give them what they asked for -If you can't give them what they asked for, offer a choice of something else OR use a first $\rightarrow$ then statement to let them know when they can have it.

When your child asks for something the wrong way (by yelling, whining, or taking something from someone), don't give them what they asked for.

-Wait until they are quiet and listening to you, then remind them how to ask nicely for something they can have
Example: “Thanks for asking so nicely! We aren’t having popsicles today though; you can have fruit snacks or a cookie.”

OR

"Thanks for asking kindly, first we have to finish all our chores, then we can have a Popsicle.”

Example: "Jimmy, you can say 'May I have fruit snacks or a cookie, please?’” 


\section{How to Give Instructions - Short, Do, and Follow Through}

When giving your child an instruction:

- Start by giving your child some positive attention or getting them to look at you; you can get on your child's level, touch their shoulder, and tell them what they're doing well at that moment. You may need to block them from playing with toys or watching the TV.

- Use short instructions

- Only give one instruction at a time

- Tell your child what to do instead of saying "Stop that" or "Don't do that" (this will help teach your child the right thing to do next time)

- Follow through on your instruction remembering to praise!

Tip: Use the phrase "Short, Do, and Follow Through" to help you remember.

When possible, use choices in your instructions.

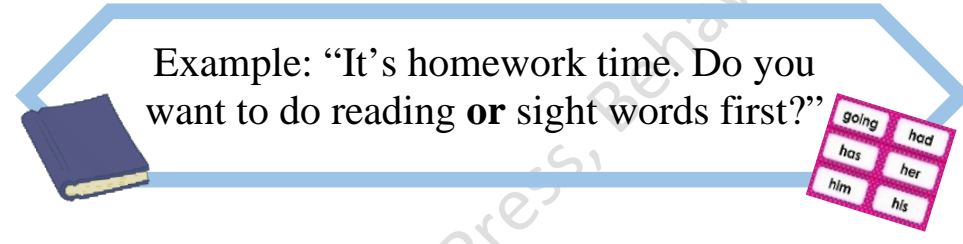

You can also use first $\rightarrow$ then statements when giving your child something to do.

Example: "First take out the trash, then you can watch TV."

\section{A good instruction:}

You want Jimmy to stop playing. "Jimmy, put your toys in the box."

\section{How to follow through: Three-Step Prompting}

He does it!

\section{He doesn't.} Great job, Jimmy!

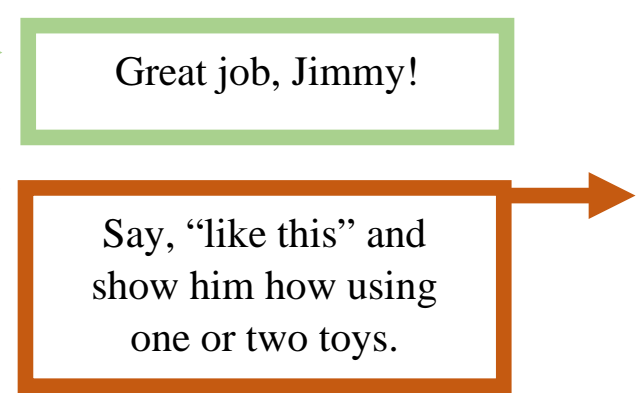

If he still doesn't do what you showed him, take Jimmy's hand in yours and do it with him.

Instructional video: https://youtu.be/xBTEE725xL4

Quiz: https://cla.auburn.edu/apmrt/foster-parents/ 


\section{How to Handle Junky Behavior - Pivot and Praise}

Follow these steps when your child is doing something annoying or disrespectful, but not dangerous. For example, you can use these steps for things like whining, rolling their eyes at you, making bodily-function noises, or teasing a sibling.

1. Don't comment on the annoying behaviors

2. If there's another person in the room doing the right thing, compliment them.

"Sally, great job using a polite voice at the dinner table."

3. If the original child stops doing the annoying thing, notice and compliment them immediately for doing the right thing!

“Jimmy, I really like how nice and polite you're being.”

If there isn't another person in the room, only do steps 1 and 3. Just wait it out and give your child specific attention for the right behavior as soon as they stop the annoying behavior.

Instructional video: https://youtu.be/p-ebezT5PKQ Quiz: https://cla.auburn.edu/apmrt/foster-parents/

\section{How to Handle Major Problem Behaviors}

Follow these steps when your child is doing something harmful or dangerous, like being aggressive, throwing a tantrum, damaging things in the house, or hitting themselves.

4. Stay calm - minimize comments on the behavior, keep your tone of voice down, minimize any damage by taking away items they may be hitting others or themselves with and standing between them and another child they could hurt.

5. Stand your ground - keep your child from getting what they want, don't give them what they're asking for while they're hitting, throwing tantrums, etc.

6. If you were giving them an instruction before they started having major problem behavior...

Follow through by guiding them through the task

If they were trying to get something they wanted before they started having major problem behavior...

Wait for them to be calm, compliment/give attention for being calm, and remind them to ask the right way for what they want (if they can have it now) or tell them when they can have it later or what they can have instead.

"Jimmy, I really like your inside voice. You can ask, 'Can I have a popsicle, please?’”
"Jimmy, thank you for sitting quietly. You can have fruit snacks today." 


\section{Best Practice Instructional Videos}

These videos are unsearchable on YouTube. You will need to use the direct link below, or visit APMRT's website. Corresponding comprehension quizzes for each video can be found on APMRT’s website as well. https://cla.auburn.edu/apmrt/foster-parents/

1. Building a Positive Environment in Your Home

Link to Video - https://youtu.be/2NPzKhApuUM

This video correlates with page 1 of the best practices written guide

\section{Giving Instructions}

Link to Video - https://youtu.be/xBTEE725xL4

This video correlates with page 2 of the best practices written guide

3. How to Handle Junk Behavior: Pivot \& Praise

Link to Video - https://youtu.be/p-ebezT5PKQ

This video correlates with page 3 section 1 of the best practices written guide

\section{How to Handle Major Problem Behavior}

Link to Video - https://youtu.be/yFsYUzO1wCw

This video correlates with page 3 section 2 of the best practices written guide 